\title{
Sustainable Biomass Glucose-Derived Porous Carbon Spheres with High Nitrogen Doping: As a Promising Adsorbent for $\mathrm{CO}_{2} / \mathrm{CH}_{4} / \mathrm{N}_{2}$ Adsorptive Separation
}

\author{
Yao Li ${ }^{1,2,+} \mathbb{D}$, Shiying Wang ${ }^{1, \dagger}$, Binbin Wang ${ }^{3, * \mathbb{D}}$, Yan Wang ${ }^{1 \mathbb{D}}$ and Jianping Wei ${ }^{1,2, *}$ \\ 1 School of Safety Science and Engineering, Henan Polytechnic University, Jiaozuo 454000, China; \\ leayao35@hpu.edu.cn (Y.L.); 211701010023@home.hpu.edu.cn (S.W.); yanwang@hpu.edu.cn (Y.W.) \\ 2 State Key Laboratory Cultivation Base for Gas Geology and Gas Control, Henan Polytechnic University, \\ Jiaozuo 454000, China \\ 3 School of Materials Science and Engineering, Henan Polytechnic University, Jiaozuo 454000, China \\ * Correspondence: wangbb@hpu.edu.cn (B.W.); weijianping@hpu.edu.cn (J.W.); Tel.: +86-391-398-6901 (B.W.); \\ +86-391-398-7885 (J.W.) \\ + These authors contributed equally to this work.
}

Received: 7 January 2020; Accepted: 13 January 2020; Published: 19 January 2020

\begin{abstract}
Separation of $\mathrm{CO}_{2} / \mathrm{CH}_{4} / \mathrm{N}_{2}$ is significantly important from the view of environmental protection and energy utilization. In this work, we reported nitrogen $(\mathrm{N})$-doped porous carbon spheres prepared from sustainable biomass glucose via hydrothermal carbonization, $\mathrm{CO}_{2}$ activation, and urea treatment. The optimal carbon sample exhibited a high $\mathrm{CO}_{2}$ and $\mathrm{CH}_{4}$ capacity, as well as a low $\mathrm{N}_{2}$ uptake, under ambient conditions. The excellent selectivities toward $\mathrm{CO}_{2} / \mathrm{N}_{2}, \mathrm{CO}_{2} / \mathrm{CH}_{4}$, and $\mathrm{CH}_{4} / \mathrm{N}_{2}$ binary mixtures were predicted by ideal adsorbed solution theory (IAST) via correlating pure component adsorption isotherms with the Langmuir-Freundlich model. At $25^{\circ} \mathrm{C}$ and 1 bar, the adsorption capacities for $\mathrm{CO}_{2}$ and $\mathrm{CH}_{4}$ were 3.03 and $1.3 \mathrm{mmol} \mathrm{g}{ }^{-1}$, respectively, and the IAST predicated selectivities for $\mathrm{CO}_{2} / \mathrm{N}_{2}(15 / 85), \mathrm{CO}_{2} / \mathrm{CH}_{4}(10 / 90)$, and $\mathrm{CH}_{4} / \mathrm{N}_{2}$ (30/70) reached $16.48,7.49$, and 3.76, respectively. These results should be attributed to the synergistic effect between suitable microporous structure and desirable $\mathrm{N}$ content. This report introduces a simple pathway to obtain $\mathrm{N}$-doped porous carbon spheres to meet the flue gas and energy gas adsorptive separation requirements.
\end{abstract}

Keywords: N-doped porous carbon spheres; sustainable biomass glucose; $\mathrm{CO}_{2}$ activation and urea treatment; gas adsorptive separation; IAST selectivity

\section{Introduction}

With the rapid development of modern society, fossil fuels such as coal and petroleum are always maintaining a heavy demand. Inevitably, the burning of fossil fuels emits a large amount of the greenhouse gas carbon dioxide $\left(\mathrm{CO}_{2}\right)$, which has led to a pressing environmental burden [1-3]. Approximately, $30 \%$ of $\mathrm{CO}_{2}$ emissions in the atmosphere comes from fossil fuel-based power plants [4]; thus, it is essential to capture and separate $\mathrm{CO}_{2}$ from flue gases (typically containing $\sim 85 \% \mathrm{~N}_{2}$ and $15 \%$ $\left.\mathrm{CO}_{2}\right)$ to limit it exhausting into the atmosphere $[5,6]$. Methane $\left(\mathrm{CH}_{4}\right)$ has a much higher global warming potential (GWP) than that of $\mathrm{CO}_{2}$, with a greenhouse effect 21 times that of $\mathrm{CO}_{2}$ and a power of damage for ozone $\left(\mathrm{O}_{3}\right) 7$ times that of $\mathrm{CO}_{2}[6,7]$. In addition, $\mathrm{CH}_{4}$ is also a clean and high-caloric-energy gas, which is considered as alternative energy sources to replace petroleum and coal. Coalbed methane $(\mathrm{CBM})$ is one kind of unconventional natural gas with a main composition of $\mathrm{CH}_{4}$, which has abundant reserves in China [8,9]. However, the utilization rate of CBM is only about $40 \%$ in China, because low-concentration $\mathrm{CBM}\left(\mathrm{CH}_{4}\right.$ less than $\left.30 \%\right)$ is usually directly emitted into the atmosphere as drainage 
gas, which is not only a waste of energy sources but also pollutes the environment [9]. Therefore, it is urgent to concentrate on $\mathrm{CH}_{4}$ in $\mathrm{CBM}$ for effective utilization [10]. Apart from $\mathrm{CH}_{4}, \mathrm{CBM}$ also contains certain $\mathrm{CO}_{2}$ and $\mathrm{N}_{2}$, which would significantly cause pipeline and equipment corrosion and reduce the heating value of the $\mathrm{CBM}[8,11]$. Thus, separation of $\mathrm{CO}_{2}$ and $\mathrm{N}_{2}$ from $\mathrm{CH}_{4}$ is highly demanded in order to effectively utilize the low-concentration CBM and alleviate atmospheric contamination.

Nowadays, many technologies have been applied for gas separation/purification, including membrane separation, cryogenic distillation, hydrate crystallization, chemical absorption, and physical adsorption-based methods. In the abovementioned technologies, pressure swing adsorption (PSA) as a promising technology has received intense interest due to its great advantages of high energy efficiency, low investment costs, and ease of control $[5,6,9,12]$. However, the property of adsorbents is the core of PSA technology, playing an important role in gas adsorption and separation. Up to now, a variety of porous adsorbents have been developed for the adsorptive separation of $\mathrm{CO}_{2} / \mathrm{N}_{2}, \mathrm{CO}_{2} / \mathrm{CH}_{4}$, and $\mathrm{CH}_{4} / \mathrm{N}_{2}$ binary mixtures, such as metal-organic frameworks (MOFs) $[9,13]$, zeolites [3,14], porous organic polymers (POPs) [15], and carbon-based materials including carbon nanotubes [16,17], graphene [18], and activated porous carbon [19-23]. Among them, porous carbon absorbents have manifested many advantages, including easy preparation, low cost, large surface area, controllable porosity and surface functionality, hydrophobicity, and resistance to both bases and acids. One attractive aspect for porous carbon adsorbents is that they can be prepared by using various cheap carbon precursors, such as waste plastic polyethylene terephthalate [19], carbon black [24,25], coal [26-28], oil sands coke [29], and various biomass [30-32]. Among these precursors, biomass materials stand out for their environmental friendliness, wide availability, low cost, and renewability, and have been extensively used as a precursor for the preparation of gas-selective adsorbents. For example, our previous work reported one waste wool-derived porous carbon with equimolar binary mixtures $\mathrm{CO}_{2} / \mathrm{CH}_{4}$ and $\mathrm{CH}_{4} / \mathrm{N}_{2}$ with a selectivity of 3.19 and 7.62 , respectively, at $25^{\circ} \mathrm{C}$ and 1 bar [31]. Yang et al. prepared porous carbon by $\mathrm{KOH}$ activation from shrimp shells for efficient $\mathrm{CO}_{2}$ capture and $\mathrm{CO}_{2} / \mathrm{N}_{2}$, $\mathrm{CO}_{2} / \mathrm{CH}_{4}$, and $\mathrm{CH}_{4} / \mathrm{N}_{2}$ separation [32]. Fan et al. synthesized a cost-effective carbonaceous sorbent from coconut shells by $\mathrm{KOH}$ activation, which exhibited a high $\mathrm{CO}_{2}$ capacity of $4.26 \mathrm{mmol} \mathrm{g}{ }^{-1}$ and $\mathrm{CO}_{2} / \mathrm{N}_{2}$ selectivity of 29 at $25{ }^{\circ} \mathrm{C}$ under atmospheric pressure [33]. Cao et al. manufactured three-dimensional porous carbon frameworks with an outstanding $\mathrm{CO}_{2}$ capture and $\mathrm{CO}_{2} / \mathrm{N}_{2}$ selectivity by the $\mathrm{KOH}$-assisted hydrothermal method from mangosteen peel waste [34]. In other words, previous works have indicated that biomass-derived porous carbons are promising adsorbents for $\mathrm{CO}_{2} / \mathrm{CH}_{4} / \mathrm{N}_{2}$ adsorption and separation. Nevertheless, the preparation of biomass-derived porous carbons for gas-selective adsorption usually uses the harsh activator $\mathrm{KOH}$, which is undesirable due to its strong inherent causticity, causing equipment corrosion and damage [35,36]. Thus, it is crucial to use a mild activation reagent of environmentally friendly nature for further development of gas-selective separation applications. Of various substances used as activators, $\mathrm{CO}_{2}$ as a physical activation agent is a good alternative, which is not toxic but can effectively etch carbon precursors to produce a microporous structure [36].

The adsorptive separation of $\mathrm{CO}_{2} / \mathrm{N}_{2}, \mathrm{CO}_{2} / \mathrm{CH}_{4}$, and $\mathrm{CH}_{4} / \mathrm{N}_{2}$ when using porous carbons as adsorbents is mainly based on both equilibrium and kinetic adsorption. Considering the gas mixture with very close physical properties (such as the same polarity and similar molecular diameter), the adsorbents should satisfy particular requirements, e.g., narrow pore size distribution (PSD) and well-polarized frameworks [37]. From a kinetic perspective, recent studies have reported that adsorbents with well-defined micropores have promising properties for separating small gas molecules that are similar in size $[10,37,38]$. On the other hand, the polarity of the adsorbent framework could enable weak interactions between the gas molecules and the polar channels, which may further help to separate the gas mixture [23,37]. Nitrogen (N)-doping is an effective method to increase the polarity of carbon frameworks [37,39], which has been reported a lot in $\mathrm{CO}_{2} / \mathrm{CH}_{4} / \mathrm{N}_{2}$ selective adsorption $[21,23,37,40,41]$. However, nowadays, most porous carbon is fine powder $(<30 \mu \mathrm{m})$ belonging to Geldart's group C classification $[42,43]$. When the carbon powders applicate in industrial 
dynamic systems, such as fixed/fluidized bed reactors, facing the challenge of plug formation, channeling, and agglomeration because of cohesive forces (such as van der Waals, electrostatic, and moisture-induced surface tension forces) existing between particles [44,45]. Inspired by Raganati and his co-workers, temperature-controlled [46] and sound-assisted [47-49] fluidization can be used to achieve a fluidization regime of these cohesive particles, which makes such fine carbon powders not only easily testable for characterization in static analysis systems, but also capable of actual use in dynamic systems.

Considering these pros and cons, in this work, we prepare N-doped porous carbon spheres for efficient $\mathrm{CO}_{2} / \mathrm{CH}_{4} / \mathrm{N}_{2}$ adsorptive separation by using sustainable biomass glucose as the raw material, environmentally friendly $\mathrm{CO}_{2}$ as the activator, and urea as the nitrogen agent. As illustrated in Figure 1, the carbon-rich precursor glucose is first converted into hydrochar spheres with the presence of cetyltrimethyl ammonium bromide (CTAB) by using the hydrothermal carbonization treatment. Then, one-step carbonization and $\mathrm{CO}_{2}$ activation proceed to form highly porous carbon spheres. These porous carbons are mixed with urea and heated in air to form highly N-doped porous carbon spheres. After $\mathrm{CO}_{2}$ activation and urea modification, the resulting carbon spheres possess a narrow PSD and high $\mathrm{N}$ content, which are used as a promising adsorbent. These porous carbon spheres exhibit a high $\mathrm{CO}_{2}\left(3.03 \mathrm{mmol} \mathrm{g}^{-1}\right)$ and $\mathrm{CH}_{4}\left(1.3 \mathrm{mmol} \mathrm{g}^{-1}\right)$ adsorption capacity, low $\mathrm{N}_{2}\left(0.4 \mathrm{mmol} \mathrm{g}^{-1}\right)$ uptake, and excellent selectivity for $\mathrm{CO}_{2} / \mathrm{N}_{2}(16.48), \mathrm{CO}_{2} / \mathrm{CH}_{4}(7.49)$, and $\mathrm{CH}_{4} / \mathrm{N}_{2}$ (3.76) binary mixtures under $25^{\circ} \mathrm{C}$ and 1 bar. This study hopes to provide viable insight for both porous carbon preparation and $\mathrm{CO}_{2} / \mathrm{CH}_{4} / \mathrm{N}_{2}$ separation application.

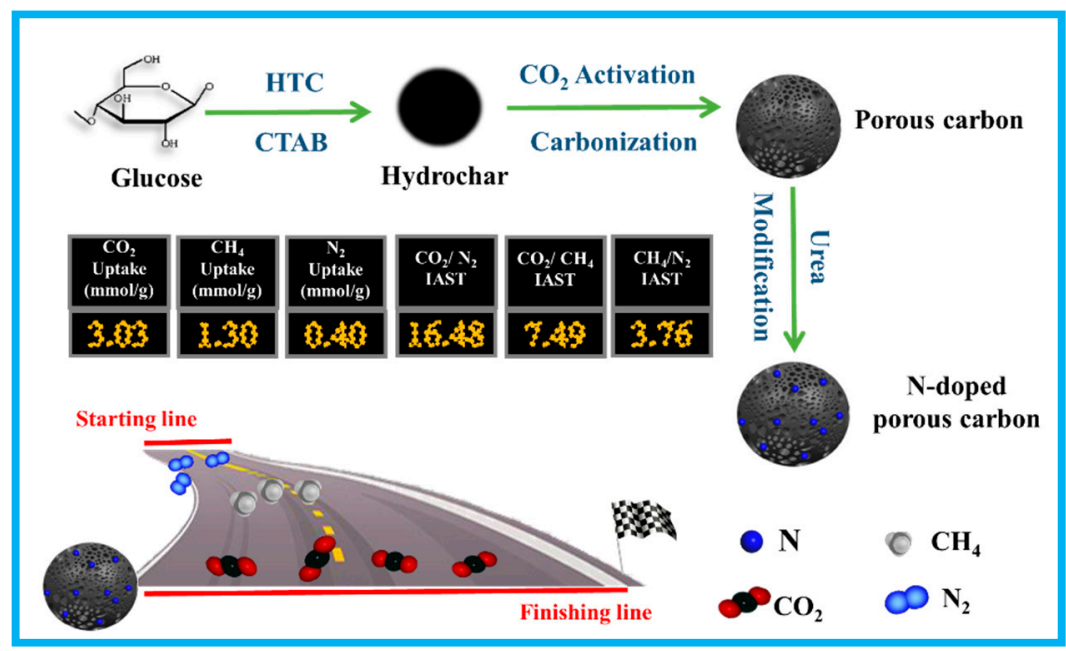

Figure 1. Schematic of the preparation of glucose-based carbon spheres and their applications.

\section{Experimental Sections}

\subsection{Materials}

D-glucose $\left(\mathrm{C}_{6} \mathrm{H}_{12} \mathrm{O}_{6}\right)$, cetyltrimethyl ammonium bromide $(\mathrm{CTAB})$, and urea $\left(\mathrm{NH}_{2} \mathrm{CONH}_{2}\right)$ were purchased from Sinopharm Chemical Reagent Co., Ltd. (Beijing, China). All chemicals were of analytical grade and were used as received without further purification.

\subsection{Preparation of Glucose-Based Hydrochar Spheres}

Glucose-based hydrochar spheres were prepared according to a previously reported method [50]. Briefly, $3.5 \mathrm{~g}$ glucose and $0.5 \mathrm{~g}$ CTAB were dissolved in $70 \mathrm{~mL}$ deionized (DI) water, and stirred with a magnetic stirrer for $2 \mathrm{~h}$ at room temperature. Then, the solution was transferred into a Teflon-lined stainless steel autoclave $(100 \mathrm{~mL})$, sealed, and maintained at $180^{\circ} \mathrm{C}$ for $6 \mathrm{~h}$. Then, the solution was cooled to room temperature. The dark brown precipitate was collected by centrifugation and washed 
with DI water and pure ethanol several times, and then dried in an oven at $80^{\circ} \mathrm{C}$ overnight. Finally, the glucose-based hydrochar spheres were denoted as HSs.

\subsection{Preparation of Porous Carbon Spheres}

The HSs were heated in a tube furnace under Ar atmosphere at a heating rate of $3{ }^{\circ} \mathrm{C} \mathrm{min}^{-1}$ first to $500{ }^{\circ} \mathrm{C}$ with a retention of $3 \mathrm{~h}$, and then to $800{ }^{\circ} \mathrm{C}$. When $800{ }^{\circ} \mathrm{C}$ was reached, flowing $\mathrm{CO}_{2}$ was introduced to activate the sample for $2 \mathrm{~h}$. Finally, the activated sample was cooled naturally to room temperature in an Ar flow. The obtained activated porous carbon spheres were recorded as ACSs. The ACSs were mixed with urea at a weight ratio of $1: 1$, heated in air at $350{ }^{\circ} \mathrm{C}$ for $2 \mathrm{~h}$, followed by washing with hot water to remove the unreacted urea and dried overnight at $80^{\circ} \mathrm{C}$. The urea-treated ACSs were named ACSs-N.

For comparison, the HSs were first modified by urea, and then carbonized only in Ar; the experimental conditions were the same as those depicted above. The as-obtained carbon spherical products were named NCSs.

\subsection{Characterizations}

Scanning electron microscopy (SEM) was performed on a Hitachi S-4800 instrument (Hitachi, Tokyo, Japan). Transmission electron microscopy (TEM) and high-resolution TEM (HR-TEM) were performed with a JEM-2100 microscope ((JEOL, Tokyo, Japan). Powder X-ray diffraction (XRD) patterns were recorded on a Bruker D8 advanced X-ray diffractometer (Bruker, Madison, WI, USA) using $\mathrm{Cu}-\mathrm{K} \alpha$ radiation $(\lambda=0.15406 \mathrm{~nm})$. Raman spectra were collected using a Renishaw inVia spectrometer (Renishaw, London, UK) with an excitation wavelength of $514 \mathrm{~nm}$. Fourier-transform infrared (FT-IR) spectra were recorded on a Nicolet 5700 (Nicolet, Madison, WI, USA), using the KBr pellet method. Elemental analysis $(\mathrm{C}, \mathrm{H}$, and $\mathrm{N})$ was performed on a dry basis using a VarioEL III Elemental Analyzer (Elementar, Hanau, Germany). The surface composition of samples was characterized by X-ray photoelectron spectroscopy (XPS), using a Thermo ESCALAB250Xi (Thermo Fisher Scientific, Waltham, MA, USA). Textural properties of the samples were measured by $\mathrm{N}_{2}$ adsorption-desorption isotherms at $-196^{\circ} \mathrm{C}$ using a Micromeritics ASAP 2420 surface area and porosimetry analyzer (Micromeritics, Norcross, GA, USA). The Brunauer-Emmett-Teller (BET) surface area $\left(S_{B E T}\right)$ was calculated using the $\mathrm{N}_{2}$ adsorption isotherm data between 0.005 and 0.05 relative pressure, the total pore volume $\left(V_{\text {tot }}\right)$ was determined from the amount of $\mathrm{N}_{2}$ adsorbed at a relative pressure of $\sim 0.99$, and the PSD was calculated using nonlocal density functional theory (NLDFT) from the $\mathrm{N}_{2}$ adsorption isotherm. The micropore volume $\left(V_{\text {micro }}\right.$, pore widths below $\left.2 \mathrm{~nm}\right)$ and narrow micropore volume $\left(\mathrm{V}_{1}\right.$, pore widths below $\left.1 \mathrm{~nm}\right)$ were calculated by the cumulative pore volume method.

\subsection{Gas Adsorption Measurements}

The adsorption-desorption isotherms for $\mathrm{CO}_{2}, \mathrm{CH}_{4}$, and $\mathrm{N}_{2}$ were measured on an intelligent gravimetric analyzer (IGA-002, Hiden, Manchester, UK) at different temperatures of 0,25 , and $45^{\circ} \mathrm{C}$ and pressures up to 1 bar. The purity of the used $\mathrm{CO}_{2}, \mathrm{CH}_{4}$, and $\mathrm{N}_{2}$ were all $99.999 \%$. Before each adsorption measurement, samples were degassed under $10^{-6}$ bar at $300^{\circ} \mathrm{C}$ for $3 \mathrm{~h}$.

\subsection{Langmuir-Freundlich (LF) Isotherm Calculation for ACSs-N}

The LF model was applied to the $\mathrm{CO}_{2}, \mathrm{CH}_{4}$, and $\mathrm{N}_{2}$ adsorption isotherms of the ACSs-N. The LF isotherm equation can be expressed as follows:

$$
q=q_{s} \times \frac{b \times p^{n}}{1+b \times p^{n}}
$$


where $q$ is the amount of gas adsorbed in equilibrium $\left(\mathrm{mmol} \mathrm{g}^{-1}\right), p$ is the equilibrium pressure (bar), $q_{s}$ is the saturation capacity $\left(\mathrm{mmol} \mathrm{g}^{-1}\right), b$ is the affinity constant, or called the LF isotherm constant $\left(\mathrm{bar}^{-1}\right)$, and $n$ is a dimensionless parameter reflecting the heterogeneity of adsorbent surfaces.

\subsection{Calculation of the Selectivity}

To investigate the adsorption selectivity of $\mathrm{CO}_{2} / \mathrm{N}_{2}, \mathrm{CO}_{2} / \mathrm{CH}_{4}$, and $\mathrm{CH}_{4} / \mathrm{N}_{2}$ on ACSs-N, the selectivity is defined as follows:

$$
S_{1 / 2}=\left[x_{1} / x_{2}\right] /\left[y_{1} / y_{2}\right]
$$

where $S_{1 / 2}$ is the selectivity factor, and $x_{1}$ and $x_{2}$ are the absolute adsorbed loadings at a partial pressure of $y_{1}$ and $y_{2}$, respectively. Ideal adsorbed solution theory (IAST) was used to calculate the binary mixture selectivity via the adsorption isotherms of a single component.

\subsection{Calculation of the Isosteric Heat of Adsorption (Qst)}

The $Q_{s t}$ of $\mathrm{CO}_{2}, \mathrm{CH}_{4}$, and $\mathrm{N}_{2}$ was calculated using the adsorption isotherms measured at 0,25 , and $45^{\circ} \mathrm{C}$ based on the Clausius-Clapeyron equation:

$$
Q_{s t}=-R T^{2}\left(\frac{\partial \ln P}{\partial T}\right)_{q},
$$

where $Q_{s t}\left(\mathrm{~kJ} \mathrm{~mol}^{-1}\right)$ is the isosteric heat of adsorption, $P(\mathrm{kPa})$ is the pressure, $T(\mathrm{~K})$ is the temperature, $R$ is the gas constant, and $q\left(\mathrm{mmol} \mathrm{g}^{-1}\right)$ is the adsorbed amount. Integrating Equation (3), with $\mathrm{q}$ as a constant, can give

$$
\ln P=\frac{Q_{s t}}{R T}+C,
$$

where $C$ is an integral constant. The $Q_{s t}$ of $\mathrm{CO}_{2}, \mathrm{CH}_{4}$, and $\mathrm{N}_{2}$ were calculated via the slopes of the linear plots of $\ln P$ vs. $1 / T$ by using the $\mathrm{CO}_{2}, \mathrm{CH}_{4}$, and $\mathrm{N}_{2}$ equilibrium isotherms data.

\section{Results and Discussion}

The morphology and structural details of the as-prepared samples were examined by SEM and TEM, as shown in Figure 2. In the hydrothermal process, soluble macromolecules polymers are first formed from the aromatization among the glucose molecules [51-53]. When the concentration of these polymers reaches a critical supersaturation point, insoluble nuclei are formed by cross-linking the macromolecules with free glucose monomers [54,55]. Then, with the help of CTAB, these nuclei adsorb surrounding molecules, leading to the growth of uniform hydrothermal carbonaceous microspheres. [50,56]. As can be seen in Figure 2a, the as-obtained hydrochar spheres (HSs) exhibited a regularly spherical shape and rough surface, which had an average diameter of about $360 \mathrm{~nm}$. After $\mathrm{CO}_{2}$ activation and urea modification, the spherical shape of the ACSs (Figure $2 b$ ) and ACSs-N (Figure 2c) could be maintained well. However, the average diameter of the spheres gradually decreased to $310 \mathrm{~nm}$ for ACSs and $180 \mathrm{~nm}$ for ACSs-N, which should be attributed to the shrinkage of the carbon skeleton in the high-temperature treatment and urea modification. Additionally, the NCSs showed a spherical morphology with an average size of $200 \mathrm{~nm}$ (Figure 2d). It is worthwhile noting that the surface of the ACSs-N was much rougher than that of the HSs, which should be attributed to the $\mathrm{CO}_{2}$ activation and urea treatment. This rough surface texture is beneficial for the gas diffusion from various orientations and further contact with the active sites [1]. TEM examination was further used to confirm the spherical morphology and structure for the ACSs-N (Figure 2e). The TEM image of an individual sphere for ACSs-N shows a dark kernel with obvious interfaces with an outer part that has lower opacity (Figure 2f). This indicates that the $\mathrm{CO}_{2}$ activation at high temperature uniformly and radially etched from the outside to the inside. Furthermore, the randomly distributed wormhole-like 
micropores can be obviously seen in the HR-TEM image (Figure 2g), which is the feature of amorphous carbon. The selected-area electron diffraction (SAED) pattern exhibits typical diffuse rings (inset in Figure 2g), also reflecting the amorphous nature of carbon.
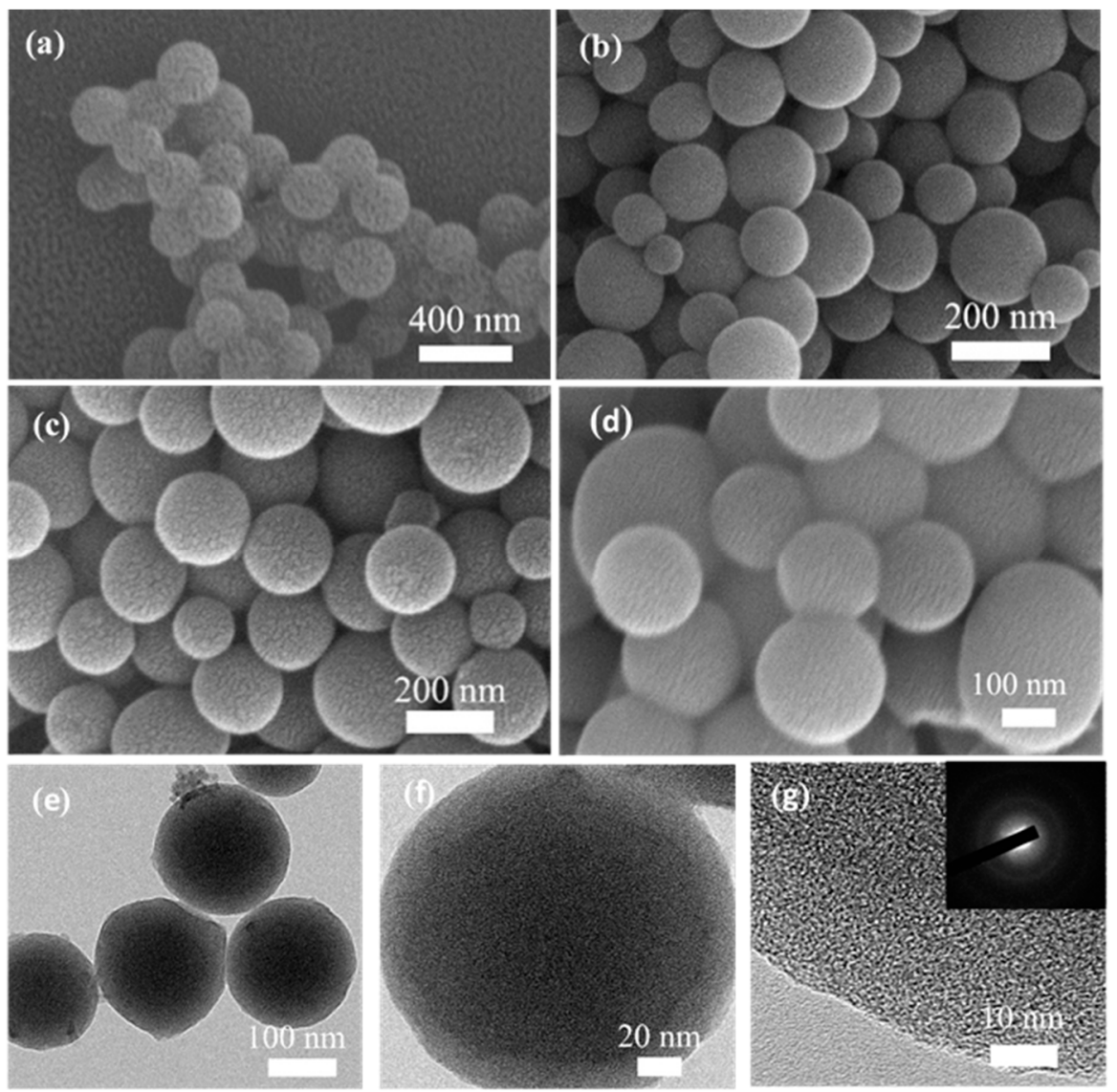

Figure 2. SEM images of (a) HSs, (b) ACSs, (c) ACSs-N, and (d) NCSs. TEM images of (e) low magnification, (f) high magnification, and (g) high-resolution (HR)-TEM for ACSs-N. The inset in Figure $2 \mathrm{~g}$ is the selected-area electron diffraction (SAED) pattern.

The phase structure of the as-prepared porous carbons NCSs, ACSs, and ACSs-N was examined by XRD and Raman spectroscopy. As displayed in Figure 3a, two typical broad peaks at around $23^{\circ}$ and $43^{\circ}$ were found for these samples, which are usually assigned to (002) and (100) diffraction patterns of the amorphous carbon [21,30]. This result is well in accordance with the Raman spectra, as shown in Figure 3b. The Raman spectra show that all these porous carbons exhibited two obvious bands at around $1330 \mathrm{~cm}^{-1}$ (D-band) and $1580 \mathrm{~cm}^{-1}$ (G-band), with the D-band associated with the disordered carbon structure and the G-band related to the graphitic carbon structure $[57,58]$. The relative intensity ratio between the $\mathrm{D}$ and $\mathrm{G}$ band $\left(I_{\mathrm{D}} / I_{\mathrm{G}}\right)$ represents the degree of defects in carbon materials, which is determined by the integral area under the peak for the $\mathrm{D}$ - and G-bands $[21,23]$. The $I_{\mathrm{D}} / I_{\mathrm{G}}$ value for NCSs, ACSs-N, and ACSs was calculated to be 1.49, 1.41, and 1.35, respectively, which suggest that more defects were generated by urea treatment. 

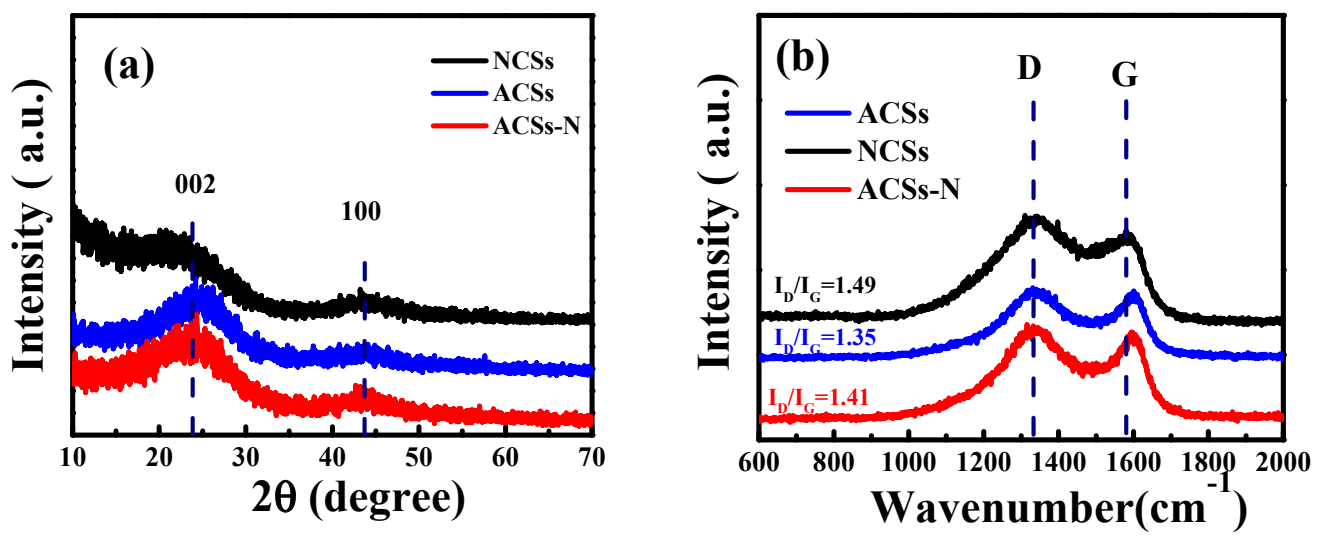

Figure 3. (a) XRD patterns and (b) Raman spectra of the porous carbons NCSs, ACSs, and ACSs-N.

The texture structure of the as-prepared porous carbons NCSs, ACSs, and ACSs-N was characterized by $\mathrm{N}_{2}$ sorption at $-196{ }^{\circ} \mathrm{C}$. The $\mathrm{N}_{2}$ adsorption-desorption isotherms, PSD curves, and corresponding parameters are illustrated in Figure 4 and Table 1. All the porous carbons exhibited a typical type-I isotherm without a hysteresis loop (Figure 4a) according to the International Union of Pure and Applied Chemistry (IUPAC) classification, which is characteristic for microporous materials [59]. The steep rise in these isotherms at low relative pressure $\left(P / P_{0}<0.01\right)$ followed by a sharp knee is due to the capillary filling of micropores [21,30]. However, there still exists some difference in the isotherms for these porous carbons prepared by different strategies. The $\mathrm{N}_{2}$ uptake amount of these porous carbons is one obvious difference following the order: ACSs $>$ ACSs-N $>$ NCGs, which is in accordance with their $S_{B E T}$, pore volume, and PSD curve. The corresponding textural parameters are summarized in Table 1 , and the ACSs had the largest $S_{B E T}, V_{\text {tot }}, V_{\text {micro }}$, and $V_{1}$ of $748 \mathrm{~m}^{2}$ $\mathrm{g}^{-1}, 0.47 \mathrm{~cm}^{3} \mathrm{~g}^{-1}, 0.27 \mathrm{~cm}^{3} \mathrm{~g}^{-1}$, and $0.21 \mathrm{~cm}^{3} \mathrm{~g}^{-1}$, respectively, while the $S_{B E T}$ of ACSs-N decreased to $697 \mathrm{~m}^{2} \mathrm{~g}^{-1}$, and the $V_{\text {tot }}, V_{\text {micro }}$, and $V_{1}$ decreased to $0.46 \mathrm{~cm}^{3} \mathrm{~g}^{-1}, 0.25 \mathrm{~cm}^{3} \mathrm{~g}^{-1}$, and $0.17 \mathrm{~cm}^{3} \mathrm{~g}^{-1}$, respectively, which is attributed to the urea treatment causing some carbon skeleton collapse and micropore coalescence of the carbon sphere interior. However, the NCSs obtained by urea treatment and high-temperature carbonization only possessed an $S_{B E T}, V_{\text {tot }}, V_{\text {micro }}$, and $V_{1}$ of $581 \mathrm{~m}^{2} \mathrm{~g}^{-1}, 0.35 \mathrm{~cm}^{3}$ $\mathrm{g}^{-1}, 0.21 \mathrm{~cm}^{3} \mathrm{~g}^{-1}$, and $0.13 \mathrm{~cm}^{3} \mathrm{~g}^{-1}$, respectively, which are much lower than those of ACSs and ACSs-N owing to the absence of $\mathrm{CO}_{2}$ activation. The textural difference for these porous carbons is further confirmed by the corresponding PSD curves (Figure 4b). The PSD curve for ACSs displays one intensity peak at $0.63 \mathrm{~nm}$ and two weak peaks at 1.0 and $1.5 \mathrm{~nm}$, respectively. For the ACSs-N, one relatively strong peak is concentrated at $0.78 \mathrm{~nm}$, while the other relatively weak peak is concentrated at $1.17 \mathrm{~nm}$. Compared to ACSs, the broadened pore size and weakened peak intensity for ACSs-N are due to the skeleton collapse and micropore coalescence of the carbon sphere interior caused by the urea treatment. As for NCSs, without $\mathrm{CO}_{2}$ activation, the PSD curve exhibits inferior strength peaks around 0.75 and $1.18 \mathrm{~nm}$, respectively. The theoretical and experimental results have shown that the narrow PSD will not only provide accommodation space for gas molecules but also confine them in micropores though the Van der Waals' force $[23,37]$. In addition, the narrow PSD will give a promising merit for separating gas molecules that are similar in size, such as $\mathrm{CO}_{2}, \mathrm{CH}_{4}$, and $\mathrm{N}_{2}$ (kinetic diameters are 3.3, 3.8, and $3.64 \AA$, respectively) [22,38]. Though the microporous structure of ACSs-N is not the best in these porous carbon spheres, it is still suitable for gas capture and separation. 

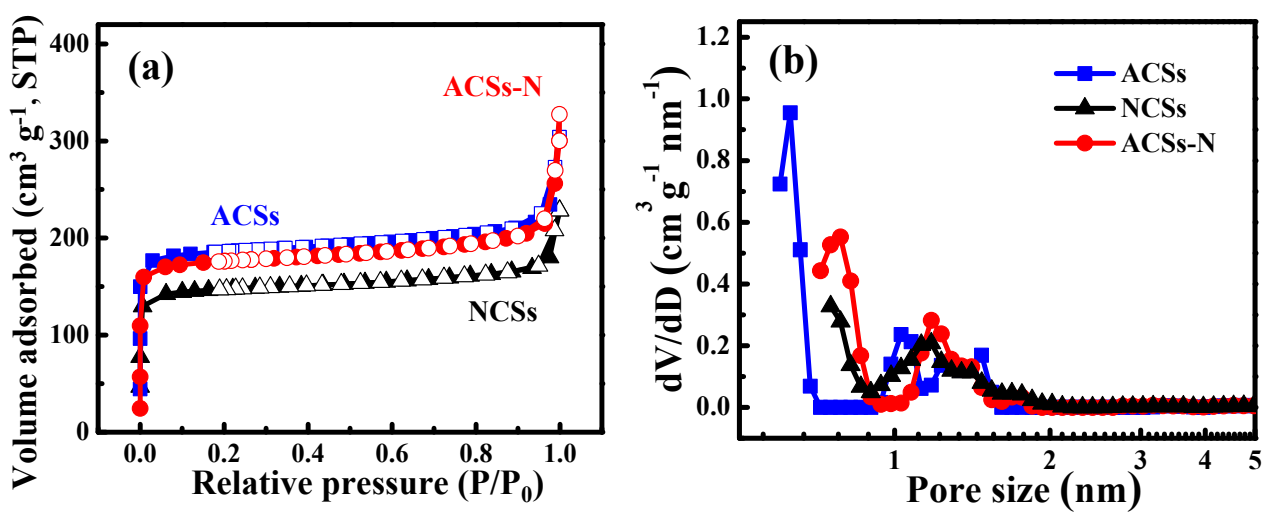

Figure 4. (a) $\mathrm{N}_{2}$ adsorption-desorption isotherms and (b) pore size distribution (PSD) curves of the porous carbons NCSs, ACSs, and ACSs-N.

Table 1. Textural parameters and chemical compositions of the porous carbons.

\begin{tabular}{|c|c|c|c|c|c|c|c|c|}
\hline \multirow[b]{2}{*}{ Sample } & \multicolumn{4}{|c|}{ Textural Parameters } & \multicolumn{4}{|c|}{ Chemical Compositions } \\
\hline & $\begin{array}{c}S_{B E T}{ }^{a} \\
\left(\mathrm{~m}^{2} \mathrm{~g}^{-1}\right)\end{array}$ & $\begin{array}{c}V_{\text {total }} \mathrm{b} \\
\left(\mathrm{cm}^{3} \mathrm{~g}^{-1}\right)\end{array}$ & $\begin{array}{c}V_{\text {micro }}{ }^{\mathrm{c}} \\
\left(\mathrm{cm}^{3} \mathrm{~g}^{-1}\right)\end{array}$ & $\begin{array}{c}V_{1}^{\mathrm{d}} \\
\left(\mathrm{cm}^{3} \mathrm{~g}^{-1}\right)\end{array}$ & $\begin{array}{c}C^{\mathrm{e}} \\
(w \mathrm{t} \%)\end{array}$ & $\begin{array}{c}N^{\mathrm{e}} \\
\left(w t^{\%} \%\right)\end{array}$ & $\begin{array}{c}H^{\mathrm{e}} \\
\left(w \mathrm{t}^{\%}\right)\end{array}$ & $\begin{array}{c}O^{\mathrm{f}} \\
\left(w t^{\%}\right)\end{array}$ \\
\hline ACSs & 748 & 0.47 & 0.27 & 0.21 & 83.84 & 1.10 & 0.04 & 15.02 \\
\hline ACSs-N & 697 & 0.46 & 0.25 & 0.17 & 75.15 & 6.50 & 0.05 & 18.30 \\
\hline NCSs & 581 & 0.35 & 0.21 & 0.13 & 67.78 & 11.48 & 1.24 & 19.50 \\
\hline
\end{tabular}

a Specific surface area calculated by Brunauer-Emmett-Teller (BET) method; ${ }^{\mathrm{b}}$ total pore volume obtained at $\mathrm{P} / \mathrm{P}_{0}$ $\sim 0.99{ }^{;}{ }^{\mathrm{c}}$ cumulative pore volume calculated in the range of pore widths up to $2 \mathrm{~nm}$; ${ }^{\mathrm{d}}$ cumulative pore volume calculated in the range of pore widths up to $1 \mathrm{~nm}$; ${ }^{\mathrm{e}}$ obtained from $C, H$, and $N$ elemental analysis; ${ }^{\mathrm{f}}$ calculated by difference.

The chemical compositions of the as-prepared porous carbons are listed in Table 1. According to the element analysis, ACSs had a negligibly low $N$ content of $1.10 \mathrm{wt} \%$, which was just from the CTAB. After urea treatment, the ACSs-N possessed a much higher $N$ content of $6.50 \mathrm{wt} . \%$. This result indicates that $N$ could be integrated into the carbon skeleton by urea treatment, while the NCSs had a very high $N$ content of $11.48 \mathrm{wt} . \%$, indicating that much more $N$ could be integrated into the hydrochar via urea treatment. Even under high-temperature carbonization, a mass of $N$ could also be reserved in the carbon skeleton. Although, the N content of ACSs-N was not as high as that of NCSs, which is still desirable among the $N$-doped porous carbons compared to those previously reported $[2,21,23,58,60]$. The FT-IR was used to characterize the bonding configuration of the $N$ atom in the porous carbons, as shown in Figure 5a. The adsorption bands at around $3430 \mathrm{~cm}^{-1}$ are ascribed to the $\mathrm{N}-\mathrm{H}$ and/or $-\mathrm{OH}$ stretching vibration $[21,30,31]$. The band at about $1620 \mathrm{~cm}^{-1}$ can be attributed to $\mathrm{N}-\mathrm{H}$ in-plane deformation vibrations or $C=C$ stretching vibrations [21,31], while the band at around $1110 \mathrm{~cm}^{-1}$ corresponds to the $C-N$ stretching vibrations [23,31]. It is noteworthy that the strength of the $N$-related bands for these porous carbons is in the order of NCSs $>$ ACSs-N $>$ ACSs, which is in accordance with the element analysis result. Additionally, the $\mathrm{C}-\mathrm{O}-\mathrm{H}$ stretching and $\mathrm{C}-\mathrm{C}$ vibration can be observed at 1384 and $1352 \mathrm{~cm}^{-1}$, respectively [21]. The adsorption bands of the FT-IR spectrum also revealed that the chemistry components of $C, N, H$, and $O$ were in the samples, which is accordance with the element analysis. The compositions of the as-produced porous carbon samples were further determined by XPS. The XPS survey spectra in Figure $5 b$ corroborate the existence of $C, N$, and $O$ in the samples. Considering the importance of the heteroatom $N$, the nature of the $N$ species on the carbon surface of ACSs-N, NCSs, and ACSs was investigated. As shown in Figure $5 \mathrm{c}-\mathrm{e}$, three sub-peaks are visible in the deconvoluted XPS N1s spectra: Pyridinic- $N(N-6)$ at $398.5 \mathrm{eV}$, pyrrolic-/pyridonic- $N(N-5)$ at $399.9 \mathrm{eV}$, and pyridine- $N$-oxide $(N-X)$ at $402 \mathrm{eV}$, respectively $[21,30,39,58]$. The presence of $N$ can not only provide Lewis basic active sites, but also increase the carbon framework polarity, which is beneficial for $\mathrm{CO}_{2} / \mathrm{CH}_{4} / \mathrm{N}_{2}$ selectivity adsorption $[21,23,35,37]$. It should be stressed that $N-5$ was 
the main type of $N$ species in the carbons, which is beneficial to boosting the $\mathrm{CO}_{2}$ capture $[21,35,60]$. Moreover, the high-resolution spectra of C1s (Figure S1a-c) can be deconvoluted into five peaks, which are respectively attributed to $C-C(284.5 \mathrm{eV}), C-O(285.4 \mathrm{eV}), C-N(285.9 \mathrm{eV}), C=O(287.5 \mathrm{eV})$, and $\mathrm{O}=\mathrm{C}-\mathrm{O}(289.4 \mathrm{eV})$ [61-64]. The split spectra of O1s (Figure S1d-f) located at 532.5 and $533.4 \mathrm{eV}$ can be assigned to $C=O$ and $C-O$, respectively $[63,65]$.
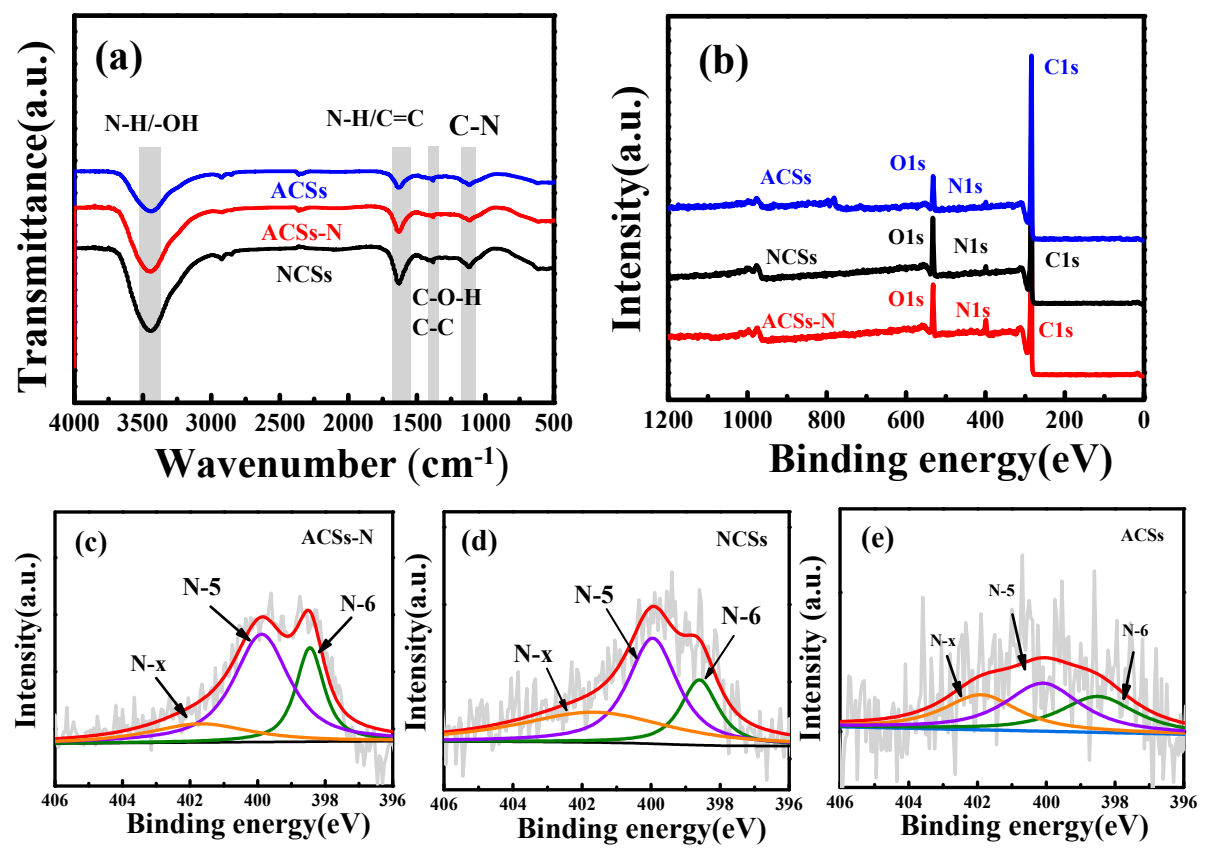

Figure 5. (a) FT-IR spectra and (b) X-ray photoelectron spectroscopy (XPS) survey spectra of the porous carbons ACSs, NCSs, and ACSs-N. The N1s high-resolution spectra of (c) ACSs-N, (d) NCSs, and (e) ACSs.

The single-component adsorption-desorption isotherms of $\mathrm{CO}_{2}, \mathrm{CH}_{4}$, and $\mathrm{N}_{2}$ on $\mathrm{NCSs}, \mathrm{ACS}$, and ACSs-N at $25^{\circ} \mathrm{C}$ and up to 1 bar are given in Figure 6. All the adsorption and desorption isotherms completely overlap with each other without any hysteresis, suggesting that the adsorbed molecules can be fully removed during the desorption process. Thus, the adsorption process is considerably reversible and these porous carbon adsorbents can be easily regenerated under vacuum without any heat energy input. Based on the adsorption isotherms, it is clear that all these porous carbons exhibited preferential adsorption of $\mathrm{CO}_{2}$ over $\mathrm{CH}_{4}$ and $\mathrm{N}_{2}$, which should be ascribed to the higher quadrupole moment and polarizability of $\mathrm{CO}_{2}$ molecules than those of $\mathrm{CH}_{4}$ and $\mathrm{N}_{2}$ [21,66]. $\mathrm{CH}_{4}$ is much more favorably adsorbed than $\mathrm{N}_{2}$, because of its higher polarizability than that of $\mathrm{N}_{2}$ molecules [6,66]. Although, the $\mathrm{N}_{2}$ molecule exhibits a higher quadrupole moment than that of $\mathrm{CH}_{4}$, which is of less influence than the difference in polarizability [10]. Moreover, the isotherms for $\mathrm{CO}_{2}$ and $\mathrm{CH}_{4}$ modestly curved, and neither reached their saturated adsorption capacity over the entire pressure range examined here. This means that much more $\mathrm{CO}_{2}$ and $\mathrm{CH}_{4}$ could be adsorbed on the adsorbents at high pressure, while the isotherms for $\mathrm{N}_{2}$ were almost linear, meaning a weak interaction between $\mathrm{N}_{2}$ and these carbon adsorbents. 

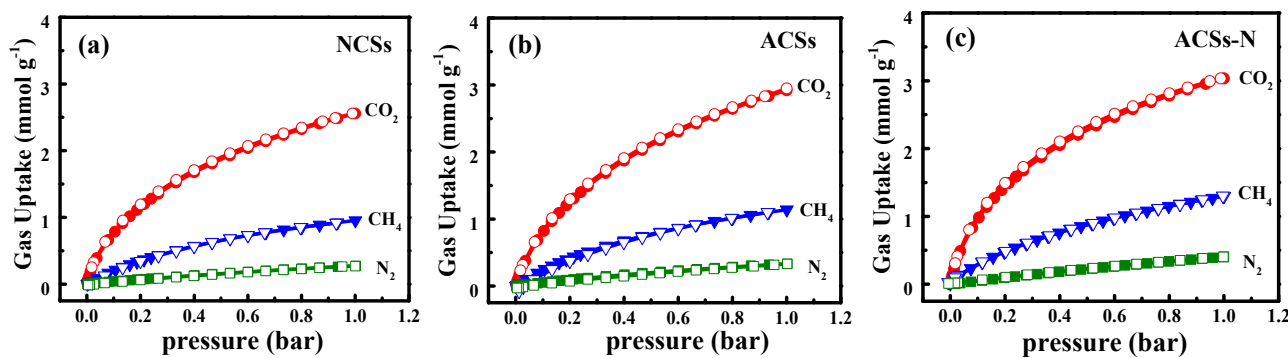

Figure 6. Adsorption (solid) and desorption (open) isotherms of $\mathrm{CO}_{2}, \mathrm{CH}_{4}$, and $\mathrm{N}_{2}$ on (a) $\mathrm{NCSs}$, (b) ACSs, and (c) ACSs-N at $25^{\circ} \mathrm{C}$.

The gas capacities of the NCSs, ASCs, and ACSs-N at $25^{\circ} \mathrm{C}$ and 1 bar are summarized in Table 2. Among them, ACSs-N displayed the best performance, and its $\mathrm{CO}_{2}$ capacity was $3.03 \mathrm{mmol} \mathrm{g}{ }^{-1}$ at $25^{\circ} \mathrm{C}$ and $1 \mathrm{bar}$, which is comparable to or higher than those of other state-of-the-art porous carbon adsorbents (see Table S1). It is well known that the favorable $\mathrm{CO}_{2}$ capacity arose from two critical factors: (i) Highly microporous structure, especially the narrow micropores $(<1 \mathrm{~nm})$, which could greatly accommodate $\mathrm{CO}_{2}$ molecules into pores; and (ii) heteroatom incorporation, especially $\mathrm{N}$-doping, which could increase the surface basicity to enhance the bonding force with acidic $\mathrm{CO}_{2}$ molecules $[23,28,29,32]$. However, the high micro-porosity is often inverse with the $N$ content. The NCSs had the highest $N$ content, but the microporous structure was poor. As for the ACSs-N, the microporous structure was excellent, while the $\mathrm{N}$ content was very low. Thus, in the same condition, the $\mathrm{CO}_{2}$ capacity for NCSs and ACSs was just 2.55 and $2.92 \mathrm{mmol} \mathrm{g}^{-1}$, respectively, and both were inferior to that of ACSs-N. The high $\mathrm{CO}_{2}$ capacity for ACSs-N should be attributed to the synergistic effect between suitable microporous structure, especially the narrow micropores $(<1 \mathrm{~nm})$, and desirable $N$ content. Additionally, special attention should be paid to the $\mathrm{CH}_{4}$ capacity owing to its importance for new energy applications. The $\mathrm{CH}_{4}$ uptakes of the three porous carbon samples under ambient conditions $\left(25^{\circ} \mathrm{C}\right.$ and $\left.1 \mathrm{bar}\right)$ follow the order of ACSs-N $\left(1.30 \mathrm{mmol} \mathrm{g}^{-1}\right)>$ ACSs $\left(1.14 \mathrm{mmol} \mathrm{g}^{-1}\right)>\mathrm{NCSs}\left(0.95 \mathrm{mmol} \mathrm{g}^{-1}\right)$. ACSs-N exhibited the best $\mathrm{CH}_{4}$ uptake performance among these porous carbon spheres, which is comparable to or higher than the values in reported in the literature for porous adsorbents (see Table S1). The $\mathrm{N}_{2}$ uptakes of the carbon samples follow the same order as those of $\mathrm{CO}_{2}$ and $\mathrm{CH}_{4}$ : ACSs-N $\left(0.4 \mathrm{mmol} \mathrm{g}^{-1}\right)$ $>\operatorname{ACSs}\left(0.33 \mathrm{mmol} \mathrm{g}^{-1}\right)>\operatorname{NCSs}\left(0.27 \mathrm{mmol} \mathrm{g}^{-1}\right)$. The high $\mathrm{CO}_{2}$ and $\mathrm{CH}_{4}$ adsorption capabilities of ACSs-N motivate us to further investigate their adsorptive separation performance for $\mathrm{CO}_{2} / \mathrm{CH}_{4} / \mathrm{N}_{2}$.

Table 2. Summary of the gas capacities of the NCSs, ASCs, and ACSs-N at $25^{\circ} \mathrm{C}$ and 1 bar.

\begin{tabular}{|c|c|c|c|}
\hline Sample & $\mathrm{CO}_{2}$ Uptake $\left(\mathrm{mmol} \mathrm{g}^{-1}\right)$ & $\mathrm{CH}_{4}$ Uptake (mmol $\left.\mathrm{g}^{-1}\right)$ & $\mathrm{N}_{2}$ Uptake (mmol $\left.\mathrm{g}^{-1}\right)$ \\
\hline NCSs & 2.55 & 0.95 & 0.27 \\
\hline ACSs & 2.92 & 1.14 & 0.33 \\
\hline ACSs-N & 3.03 & 1.30 & 0.40 \\
\hline
\end{tabular}

The pure gas adsorption isotherms of $\mathrm{CO}_{2}, \mathrm{CH}_{4}$, and $\mathrm{N}_{2}$ on ACSs-N at three temperatures $\left(0,25\right.$, and $\left.45^{\circ} \mathrm{C}\right)$ are plotted in Figure $7 \mathrm{a}-\mathrm{c}$, respectively. From these figures, it can be seen that temperature and pressure had opposite effects on the gas $\left(\mathrm{CO}_{2}, \mathrm{CH}_{4}\right.$, and $\left.\mathrm{N}_{2}\right)$ adsorption capacity. Indeed, the gas adsorption capacity increased with the pressure, which is in accordance with the fact that pressure is the thermodynamic driving force of the adsorption process [25]. On the contrary, the amount of adsorbed gas was reduced with the increase in adsorption temperature, which is in agreement with the adsorption process being exothermic [25]. The adsorption mechanisms for these three gases $\left(\mathrm{CO}_{2}, \mathrm{CH}_{4}\right.$, and $\left.\mathrm{N}_{2}\right)$ were different. The critical temperatures of $\mathrm{CH}_{4}$ and $\mathrm{N}_{2}$ were 126 and $124 \mathrm{~K}$, respectively, which are lower than the experimental temperature. Therefore, the adsorption of $\mathrm{CH}_{4}$ and $\mathrm{N}_{2}$ was monolayer supercritical adsorption. However, the critical temperature of $\mathrm{CO}_{2}$ was equal to $304.3 \mathrm{~K}$, which is closer to the experimental range. Therefore, the adsorption process 
included supercritical adsorption and subcritical adsorption. The Langmuir-Freundlich (LF) model is a combination of the Langmuir and the Freundlich isotherm models for predicting the behavior of heterogeneous adsorption systems [25]. As the N-doped porous carbons obtained in this work were not homogeneous, all the isotherms correlated with the LF model. The coefficient of determination $\mathrm{R}^{2}$ and the parameters are listed in Table 3. All $\mathrm{R}^{2}$ values in Table 3 are above 0.999, indicating that the experimental data can agree well with the LF equation. It is also clear from Figure 7 that there is good agreement between the model fitting and the experimental adsorption data. To highlight the gas adsorption performance of ACSs-N, we further measured the gas adsorption isotherms of $\mathrm{CO}_{2}$, $\mathrm{CH}_{4}$, and $\mathrm{N}_{2}$ on ACSs-N under high pressure (Figure S2). The gas capacities of ACSs-N at different temperatures $\left(0,25\right.$, and $\left.45^{\circ} \mathrm{C}\right)$ at 19 bar are summarized in Table S2. From Figure S2, it can be seen that the gas uptakes increased very slow when the pressure reached 16 bar, the adsorption isotherms almost reaching plateau. The high-pressure adsorption data agree well with the LF modeled fittings, further indicating the correct LF equation parameters.
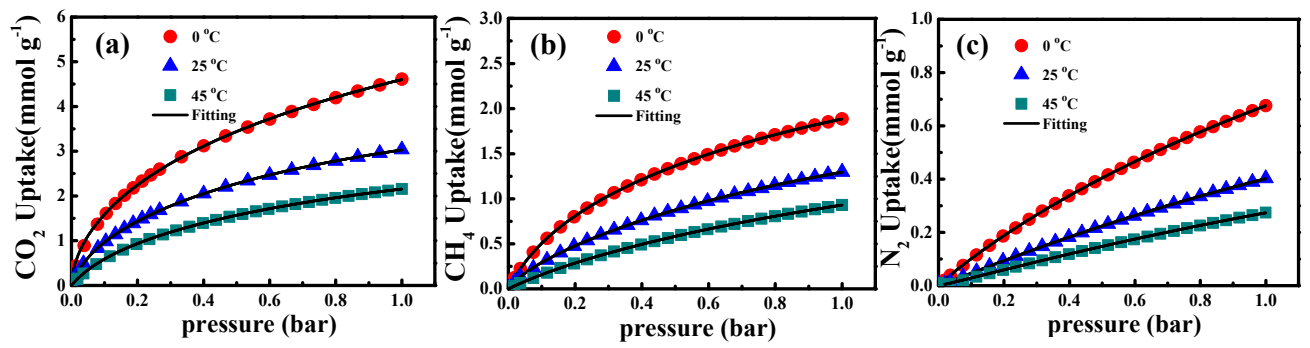

Figure 7. Adsorption isotherms of (a) $\mathrm{CO}_{2}$, (b) $\mathrm{CH}_{4}$, and (c) $\mathrm{N}_{2}$ on ACSs-N. The marker points represent the experimental data, while the black solid lines correspond to Langmuir-Freundlich equation fittings.

Table 3. Equation parameters for the Langmuir-Freundlich isotherm model on ACSs-N.

\begin{tabular}{cccccc}
\hline Adsorbate & Temp. $\left({ }^{\circ} \mathbf{C}\right)$ & $\boldsymbol{q}_{\mathbf{s}}$ & $\boldsymbol{b}$ & $\boldsymbol{n}$ & $\boldsymbol{R}^{\mathbf{2}}$ \\
\hline \multirow{2}{*}{$\mathrm{CO}_{2}$} & 273 & 6.28199 & 1.84997 & 0.72764 & 0.99990 \\
& 298 & 5.97195 & 1.00124 & 0.70470 & 0.99900 \\
& 318 & 5.74151 & 0.63787 & 0.72580 & 0.99900 \\
\hline \multirow{2}{*}{$\mathrm{CH}_{4}$} & 273 & 4.53961 & 0.69512 & 0.74049 & 0.99900 \\
& 298 & 4.22490 & 0.42287 & 0.78157 & 0.99990 \\
& 318 & 3.96414 & 0.29156 & 0.82416 & 0.99999 \\
\hline \multirow{2}{*}{$\mathrm{N}_{2}$} & 273 & 3.53500 & 0.24440 & 0.83413 & 0.99990 \\
& 298 & 3.18912 & 0.17080 & 0.82522 & 0.99900 \\
& 318 & 2.81950 & 0.10433 & 0.94821 & 0.99990 \\
\hline
\end{tabular}

The ideal adsorbed solution theory (IAST) proposed by Myers and Praunitz [67] is a thermodynamic approach assuming the adsorbed phase forms an ideal solution, where there are no interactions between the adsorbate molecules, and the spreading pressures of the components are equal at constant temperature [68]. IAST has been widely used to examine the binary gas mixture selective adsorption behavior from pure component isotherms [69-72]. Herein, the LF model was combined with IAST to predict the selectivity of ACSs-N for binary mixtures $\left(\mathrm{CO}_{2} / \mathrm{N}_{2}, \mathrm{CO}_{2} / \mathrm{CH}_{4}\right.$, and $\left.\mathrm{CH}_{4} / \mathrm{N}_{2}\right)$. The gas pairs and proportions investigated in this work, $\mathrm{CO}_{2} / \mathrm{N}_{2}(15 / 85), \mathrm{CO}_{2} / \mathrm{CH}_{4}(10 / 90)$, and $\mathrm{CH}_{4} / \mathrm{N}_{2}$ (30/70), were designed to typical flue gas, and energy-related mixed gas (such as CBM, natural gas, and biogas). The selectivity for each binary mixture at 0,25 , and $45^{\circ} \mathrm{C}$ on ACSs-N is plotted as a function of total bulk pressure in Figure 8. For a binary mixture of $\mathrm{CO}_{2}$ and $\mathrm{N}_{2}$, the selectivity decreased with the pressure, obtaining about $18.18\left(0^{\circ} \mathrm{C}\right), 16.48\left(25^{\circ} \mathrm{C}\right)$, and $19.49\left(45^{\circ} \mathrm{C}\right)$ at 1 bar (Figure $\left.8 \mathrm{a}\right)$. The $\mathrm{CO}_{2} / \mathrm{N}_{2}$ selectivity displayed by ACSs-N was higher those reported on sOMC $\left(12.7\right.$ at $0{ }^{\circ} \mathrm{C}$ and 11.3 at $\left.25^{\circ} \mathrm{C}\right)[6]$, WNPC-3 $\left(16\right.$ at $25^{\circ} \mathrm{C}$ ) [40], AC-PAIN-F (18.97 at $\left.25^{\circ} \mathrm{C}\right)$, and AC-PANI-S $\left(6.1\right.$ at $\left.25^{\circ} \mathrm{C}\right)$ [73], in the similar condition. Figure $8 \mathrm{~b}$ shows that the $\mathrm{CO}_{2} / \mathrm{CH}_{4}$ selectivity slightly increased with the pressure 
increase at $0{ }^{\circ} \mathrm{C}$, whereas it decreased with the pressure increase at 25 and $45^{\circ} \mathrm{C}$. Under $1 \mathrm{bar}, \mathrm{CO}_{2} / \mathrm{CH}_{4}$ selectivities of $8.19,7.49$, and 6.62 were reached on ACSs-N at 0,25 , and $45^{\circ} \mathrm{C}$, respectively. They surpassed the values reported for sOMC (3.4 and 2.9 at 0 and $25^{\circ} \mathrm{C}$, respectively) [6] and SNMC-2-600 (6.3 and 4.3 at 0 and $25{ }^{\circ} \mathrm{C}$, respectively) [23]. When it comes to the $\mathrm{CH}_{4} / \mathrm{N}_{2}$ separation, the selectivity of $\mathrm{CH}_{4}$ over $\mathrm{N}_{2}$ gradually decreased as the pressure increased, similar to the case of $\mathrm{CO}_{2} / \mathrm{N}_{2}$ selectivity, as shown in Figure 8c. At 1 bar, the $\mathrm{CH}_{4} / \mathrm{N}_{2}$ selectivity obtained at $4.32\left({ }^{\circ} \mathrm{C}\right), 3.76\left(25^{\circ} \mathrm{C}\right)$, and 4.62 $\left(45^{\circ} \mathrm{C}\right)$ was larger or comparable to those found on many porous carbons including sOMC (3.8 at 25 $\left.{ }^{\circ} \mathrm{C}\right)$ [6], OTSS-2-450 (4.9 at $\left.25^{\circ} \mathrm{C}\right)$ [21], SNMC-2-600 (4.6 and 4.2 at 0 and $\left.25^{\circ} \mathrm{C}\right)$ [23], and ClCTF-1-400 (4.6 at $25^{\circ} \mathrm{C}$ ) [37]. These comparison results suggest the great potential of ACSs- $\mathrm{N}$ in $\mathrm{CO}_{2} / \mathrm{CH}_{4} / \mathrm{N}_{2}$ adsorptive separation systems.
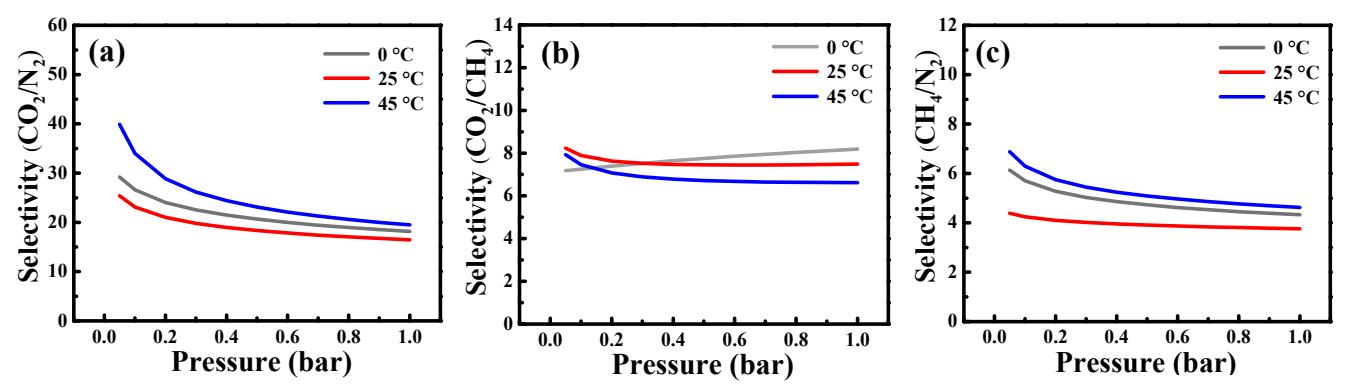

Figure 8. IAST-predicted adsorption selectivities of binary mixtures for (a) $\mathrm{CO}_{2} / \mathrm{N}_{2}(15 / 85),(\mathbf{b}) \mathrm{CO}_{2} / \mathrm{CH}_{4}$ (10/90), and (c) $\mathrm{CH}_{4} / \mathrm{N}_{2}(30 / 70)$ on ACSs-N.

Isosteric heat of adsorption (Qst) is an important thermodynamic parameter to evaluate the interaction between adsorbate gas molecules and an adsorbent $[5,6,38]$, which can be estimated from the adsorption isotherms at different temperatures by using the Clausius-Clapeyron equation.

Figure 9 shows the Qst of $\mathrm{CO}_{2}, \mathrm{CH}_{4}$, and $\mathrm{N}_{2}$ on ACSs-N. It can be seen that the Qst of $\mathrm{CH}_{4}$ and $\mathrm{N}_{2}$ gradually decreased with the increase in surface coverage; however, the Qst of $\mathrm{CO}_{2}$ was almost unchanged. A decrease in Qst with gas loading is characteristic of heterogeneous adsorbents; whereas a constant Qst with gas loading indicates a balance between the strength of cooperative gas-gas interactions and the degree of heterogeneity of gas-solid interactions [74-76]. The ACSs-N had a heterogenous surface for the adsorption of $\mathrm{CO}_{2}, \mathrm{CH}_{4}$, and $\mathrm{N}_{2}$ with the Qst range of 38.7-38.5 $\left(\mathrm{CO}_{2}\right), 28.6-22.5\left(\mathrm{CH}_{4}\right)$, and $25.0-20.6 \mathrm{~kJ} \mathrm{mmol}^{-1}\left(\mathrm{~N}_{2}\right)$, respectively, from low coverage to saturation. The Qst follows the order of $\mathrm{CO}_{2}>\mathrm{CH}_{4}>\mathrm{N}_{2}$, suggesting that the interaction of $\mathrm{CO}_{2}$ with ACSs-N was stronger than that of $\mathrm{CH}_{4}$ with $\mathrm{N}_{2}$; meanwhile, the interaction of $\mathrm{CH}_{4}$ with ACSs-N was stronger than that of $\mathrm{N}_{2}$. Notably, the highest Qst for $\mathrm{CO}_{2}$ was still in the value range of the physisorption process, which means that the desorption process was simple and reversible. The above Qst characteristics make ACSs-N a promising adsorbent for $\mathrm{CO}_{2} / \mathrm{CH}_{4} / \mathrm{N}_{2}$ separation.

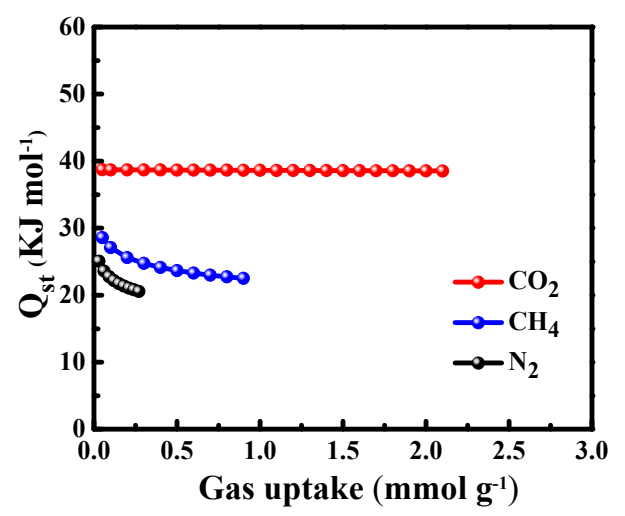

Figure 9. Isosteric heats of adsorption for $\mathrm{CO}_{2}, \mathrm{CH}_{4}$, and $\mathrm{N}_{2}$ on the ACSs-N. 


\section{Conclusions}

In summary, the ACSs-N were prepared by $\mathrm{CO}_{2}$ physical activation of glucose-derived hydrochar and urea treatment, which was used for efficient $\mathrm{CO}_{2}$ and $\mathrm{CH}_{4}$ adsorption and $\mathrm{CO}_{2} / \mathrm{CH}_{4} / \mathrm{N}_{2}$ adsorptive separation. The obtained ACSs-N possessed a large $S_{B E T}$ of $697 \mathrm{~m}^{2} \mathrm{~g}^{-1}$, suitable $V_{\text {tot }}, V_{\text {mico }}$, and $V_{1}$ of $0.46,0.25$, and $0.21 \mathrm{~m}^{3} \mathrm{~g}^{-1}$, respectively, and desirable $N$ content of $6.5 \mathrm{wt} \%$. On account of the synergistic effect between suitable microporous structure and desirable $N$ content, under $25^{\circ} \mathrm{C}$ and 1 bar, the capacities of ACSs-N for $\mathrm{CO}_{2}$ and $\mathrm{CH}_{4}$ were 3.03 and $1.3 \mathrm{mmol} \mathrm{g}^{-1}$, respectively, and the IAST predicted selectivities for $\mathrm{CO}_{2} / \mathrm{N}_{2}(15 / 85), \mathrm{CO}_{2} / \mathrm{CH}_{4}(10 / 90)$, and $\mathrm{CH}_{4} / \mathrm{N}_{2}(30 / 70)$ binary mixtures reached 16.48, 7.49, and 3.76, respectively. These results make ACSs-N a highly promising adsorbent for $\mathrm{CO}_{2}$ and $\mathrm{CH}_{4}$ capture and $\mathrm{CO}_{2} / \mathrm{CH}_{4} / \mathrm{N}_{2}$ adsorptive separation. Given the sustainability and environmental friendliness of the raw material, this work provides a useful approach to prepare relatively inexpensive $N$-doped porous carbon adsorbents for industrial applications.

Supplementary Materials: The following are available online at http://www.mdpi.com/2079-4991/10/1/174/s1, Figure S1: XPS high-resolution of $(\mathrm{a}, \mathrm{b}, \mathrm{c}) \mathrm{C} 1 \mathrm{~s}$ and $(\mathrm{d}, \mathrm{e}, \mathrm{f}) \mathrm{O} 1 \mathrm{~s}$ for the porous carbon samples ACSs-N, NCSs and ACSs, Figure S2: Adsorption isotherms of (a) $\mathrm{CO}_{2}$, (b) $\mathrm{CH}_{4}$, and (c) $\mathrm{N}_{2}$ on ACSs-N at high pressure. The marker points represent the experimental data, while the black solid lines correspond to Langmuir-Freundlich equation fittings, Table S1: The gas adsorption performance for porous materials from reported results, Table S2: Summary of the gas capacities of the ACSs-N under high pressure.

Author Contributions: Y.L. proposed and planned the research, and supervised the experiments; S.W. performed the experiment and analyzed the data; B.W. and J.W. improved the data analysis; Y.W. polished and edited the English. All the authors discussed the results and participated in the writing of the manuscript. All authors have read and agree to the published version of the manuscript.

Funding: This work was supported by a Project funded by the China Postdoctoral Science Foundation (2018M632775), NSFC (No. U1804156, 51574112, 51974109), Henan Province Colleges and Universities Key Research Project (18A620002, 18A150005), State Key Laboratory Cultivation Base for Gas Geology and Gas Control (Henan Polytechnic University) (WS2018A05), Innovative Research Team in University of Ministry of Education of China (IRT_16R22), Henan Polytechnic University Doctor Foundation (660107/017) and Program for Innovative Research Team of Henan Polytechnic University (T2018-2).

Conflicts of Interest: The authors declare no competing financial interest.

\section{References}

1. Li, Y.; Zou, B.; Hu, C.W.; Cao, M.H. Nitrogen-doped porous carbon nanofiber webs for efficient $\mathrm{CO}_{2}$ capture and conversion. Carbon 2016, 99, 79-89. [CrossRef]

2. Kim, H.S.; Kang, M.S.; Lee, S.H.; Lee, Y.-W.; Yoo, W.C. N-doping and ultramicroporosity-controlled crab shell derived carbons for enhanced $\mathrm{CO}_{2}$ and $\mathrm{CH}_{4}$ sorption. Microporous Mesoporous Mater. 2018, 272, 92-100. [CrossRef]

3. Guo, Y.; Sun, T.J.; Gu, Y.M.; Liu, X.W.; Ke, Q.L.; Wei, X.L.; Wang, S.D. Rational synthesis of chabazite (CHA) zeolites with controlled $\mathrm{Si} / \mathrm{Al}$ ratio and their $\mathrm{CO}_{2} / \mathrm{CH}_{4} / \mathrm{N}_{2}$ adsorptive separation performances. Asian J. Chem. 2018, 13, 3222-3230. [CrossRef]

4. Plaza, M.G.; Pevida, C.; Arenillas, A.; Rubiera, F.; Pis, J.J. $\mathrm{CO}_{2}$ capture by adsorption with nitrogen enriched carbons. Fuel 2007, 86, 2204-2212. [CrossRef]

5. Wang, X.J.; Yuan, B.Q.; Zhou, X.; Xia, Q.B.; Li, Y.W.; An, D.L.; Li, Z. Novel glucose-based adsorbents (Glc-Cs) with high $\mathrm{CO}_{2}$ capacity and excellent $\mathrm{CO}_{2} / \mathrm{CH}_{4} / \mathrm{N}_{2}$ adsorption selectivity. Chem. Eng. J. 2017, 327, 51-59. [CrossRef]

6. Yuan, B.; Wu, X.F.; Chen, Y.X.; Huang, J.H.; Luo, H.M.; Deng, S.G. Adsorption of $\mathrm{CO}_{2}, \mathrm{CH}_{4}$, and $\mathrm{N}_{2}$ on ordered mesoporous carbon: Approach for greenhouse gases capture and biogas upgrading. Environ. Sci. Technol. 2013, 47, 5474-5480. [CrossRef]

7. Hao, X.F.; Li, Z.; Hu, H.J.; Liu, X.Q.; Huang, Y.Q. Separation of $\mathrm{CH}_{4} / \mathrm{N}_{2}$ of low concentrations from coal bed gas by sodium-modified clinoptilolite. Front. Chem. 2018, 6, 633. [CrossRef]

8. Xue, C.L.; Cheng, W.P.; Hao, W.M.; Ma, J.H.; Li, R.F. $\mathrm{CH}_{4} / \mathrm{N}_{2}$ adsorptive separation on zeolite X/AC composites. J. Chem. 2019, 2019, 2078360. [CrossRef] 
9. Li, Q.Z.; Yuan, C.C.; Zhang, G.Y.; Liu, J.F.; Zheng, Y.N. Effects of doping $\mathrm{Mg}^{2+}$ on the pore structure of MIL-101 and its adsorption selectivity for $\mathrm{CH}_{4} / \mathrm{N}_{2}$ gas mixtures. Fuel 2019, 240, 206-218. [CrossRef]

10. Guo, Y.; Hu, J.J.; Liu, X.W.; Sun, T.J.; Zhao, S.S.; Wang, S.D. Scalable solvent-free preparation of $\left[\mathrm{Ni}_{3}(\mathrm{HCOO})_{6}\right]$ frameworks for highly efficient separation of $\mathrm{CH}_{4}$ from $\mathrm{N}_{2}$. Chem. Eng. J. 2017, 327, 564-572. [CrossRef]

11. Qu, D.L.; Yang, Y.; Lu, K.; Yang, L.; Li, P.; Yu, J.G.; Ribeiro, A.M.; Rodrigues, A.E. Microstructure effect of carbon materials on the low-concentration methane adsorption separation from its mixture with nitrogen. Adsorption 2018, 24, 357-369. [CrossRef]

12. Szabelski, P.; Nieszporek, K. Adsorption of gases on strongly heterogeneous surfaces. The integral equation approach and simulations. J. Phys. Chem. B 2003, 107, 12296-12302.

13. Niu, Z.; Cui, X.L.; Pham, T.; Lan, P.C.; Xing, H.B.; Forrest, K.A.; Wojtas, L.; Space, B.; Ma, S.Q. A metal-organic framework based methane nano-trap for the capture of coal-mine methane. Angew. Chem. Int. Ed. 2019, 58, 10138-10141. [CrossRef]

14. Jensen, N.K.; Rufford, T.E.; Watson, G.; Zhang, D.K.; Chan, K.I.; May, E.F. Screening zeolites for gas separation applications involving methane, nitrogen, and carbon dioxide. J. Chem. Eng. Data 2011, 57, 106-113. [CrossRef]

15. Yang, Z.L.; Peng, X.; Cao, D.P. Carbon dioxide capture by PAFs and an efficient strategy to fast screen porous materials for gas separation. J. Phys. Chem. C 2013, 117, 8353-8364. [CrossRef]

16. Dumée, L.; Hill, M.R.; Duke, M.; Velleman, L.; Sears, K.; Schütz, J.; Finn, N.; Gray, S. Activation of gold decorated carbon nanotube hybrids for targeted gas adsorption and enhanced catalytic oxidation. J. Mater. Chem. 2012, 22, 9374-9378. [CrossRef]

17. Gholidoust, A.; Maina, J.W.; Merenda, A.; Schützc, J.A.; Kong, L.X.; Hashisho, Z.; Dumée, L.F. $\mathrm{CO}_{2}$ sponge from plasma enhanced seeded growth of metal organic frameworks across carbon nanotube bucky-papers. Sep. Purif. Technol. 2019, 209, 571-579. [CrossRef]

18. Ali, I.; Basheer, A.A.; Mbianda, X.Y.; Burakove, A.; Galunine, E.; Burakova, I.; Mkrtchyan, E.; Tkacheve, A.; Grachev, V. Graphene based adsorbents for remediation of noxious pollutants from wastewater. Environ. Int. 2019, 127, 160-180. [CrossRef]

19. Nasruddin, Y.; Sanal, A.; Bernama, A.; Haris, F.; Ramadhan, I.T. Preparation of activated carbon from waste plastics polyethylene terephthalate as adsorbent in natural gas storage. Mater. Sci. Eng. 2017, 176, 012055.

20. Shao, X.H.; Feng, Z.H.; Xue, R.S.; Ma, C.C.; Wang, W.C.; Peng, X.; Cao, D.P. Adsorption of $\mathrm{CO}_{2}, \mathrm{CH}_{4}, \mathrm{CO}_{2} / \mathrm{N}_{2}$ and $\mathrm{CO}_{2} / \mathrm{CH}_{4}$ in novel activated carbon beads: Preparation, measurements and simulation. AIChE J. 2011, 57, 3042-3051. [CrossRef]

21. Zhang, Y.; Liu, L.; Zhang, P.X.; Wang, J.; Xu, M.; Deng, Q.; Zeng, Z.L.; Deng, S.G. Ultra-high surface area and nitrogen-rich porous carbons prepared by a low-temperature activation method with superior gas selective adsorption and outstanding supercapacitance performance. Chem. Eng. J. 2019, 355, 309-319. [CrossRef]

22. Park, J.; Attia, N.F.; Jung, M.; Lee, M.E.; Lee, K.; Chung, J.; Oh, H. Sustainable nanoporous carbon for $\mathrm{CO}_{2}$, $\mathrm{CH}_{4}, \mathrm{~N}_{2}, \mathrm{H}_{2}$ adsorption and $\mathrm{CO}_{2} / \mathrm{CH}_{4}$ and $\mathrm{CO}_{2} / \mathrm{N}_{2}$ separation. Energy 2018, 158, 9-16. [CrossRef]

23. Zhang, P.X.; Zhong, Y.; Ding, J.; Wang, J.; Xu, M.; Deng, Q.; Zeng, Z.L.; Deng, S.G. A new choice of polymer precursor for solvent-free method: Preparation of N-enriched porous carbons for highly selective $\mathrm{CO}_{2}$ capture. Chem. Eng. J. 2019, 355, 963-973. [CrossRef]

24. Raganati, F.; Alfe, M.; Gargiulo, V.; Chirone, R.; Ammendola, P. Kinetic study and breakthrough analysis of the hybrid physical/chemical $\mathrm{CO}_{2}$ adsorption/desorption behavior of a magnetite-based sorbent. Chem. Eng. J. 2019, 372, 526-535. [CrossRef]

25. Raganati, F.; Alfe, M.; Gargiulo, V.; Chirone, R.; AmmendolaIstituto, P. Isotherms and thermodynamics of $\mathrm{CO}_{2}$ adsorption on a novel carbon-magnetite composite sorbent. Chem. Eng. Res. Des. 2018, 134, 540-552. [CrossRef]

26. Byamba-Ochir, N.; Shim, W.G.; Balathanigaimani, M.S.; Moon, H. High density Mongolian anthracite based porous carbon monoliths for methane storage by adsorption. Appl. Energy 2017, 190, 257-265. [CrossRef]

27. Sun, F.; Gao, J.; Yang, Y.; Zhu, Y.; Wang, L.; Pi, X.; Liu, X.; Qu, Z.; Wu, S.; Qin, Y. One-step ammonia activation of Zhundong coal generating nitrogen-doped microporous carbon for gas adsorption and energy storage. Carbon 2016, 109, 747-754. [CrossRef]

28. Adelodun, A.A.; Ngila, J.C.; Kim, D.-G.; Jo, Y.-M. Isotherm, thermodynamic and kinetic studies of selective $\mathrm{CO}_{2}$ adsorption on chemically modified carbon surfaces. Aerosol Air Qual. Res. 2017, 16, 3312-3329. [CrossRef] 
29. Gholidoust, A.; Atkinson, J.D.; Hashisho, Z. Enhancing $\mathrm{CO}_{2}$ adsorption via amine-impregnated activated carbon from oil sands coke. Energy Fuels 2017, 31, 1756-1763. [CrossRef]

30. Yue, L.M.; Rao, L.L.; Wang, L.L.; An, L.Y.; Hou, C.Y.; Ma, C.D.; DaCosta, H.; Hu, X. Efficient CO $_{2}$ adsorption on nitrogen-doped porous carbons derived from D-glucose. Energy Fuels 2018, 32, 6955-6963. [CrossRef]

31. Li, Y.; Xu, R.; Wang, B.B.; Wei, J.P.; Wang, L.Y.; Shen, M.Q.; Yang, J. Enhanced N-doped porous carbon derived from $\mathrm{KOH}$-activated waste wool: A promising material for selective adsorption of $\mathrm{CO}_{2} / \mathrm{CH}_{4}$ and $\mathrm{CH}_{4} / \mathrm{N}_{2}$. Nanomaterials 2019, 9, 266. [CrossRef] [PubMed]

32. Yang, F.Q.; Wang, J.; Liu, L.; Zhang, P.X.; Yu, W.K.; Deng, Q.; Zeng, Z.L.; Deng, S.G. Synthesis of porous carbons with high $\mathrm{N}$-content from shrimp shells for efficient $\mathrm{CO}_{2}$ capture and gas separation. ACS Sustain. Chem. Eng. 2018, 6, 15550-15559. [CrossRef]

33. Yang, M.L.; Guo, L.P.; Hu, G.S.; Hu, X.; Xu, L.Q.; Chen, J.; Dai, W.; Fan, M.H. Highly cost-effective nitrogen-doped porous coconut shell-based $\mathrm{CO}_{2}$ sorbent synthesized by combining ammoxidation with KOH activation. Envion. Sci. Technol. 2015, 49, 7063-7070. [CrossRef] [PubMed]

34. Li, Y.; Wang, X.; Cao, M.H. Three-dimensional porous carbon frameworks derived from mangosteen peel waste as promising materials for $\mathrm{CO}_{2}$ capture and supercapacitors. J. CO2 Util. 2018, 27, 204-216. [CrossRef]

35. Rao, L.L.; Yue, L.M.; Wang, L.L.; Wu, Z.Z.; Ma, C.D.; An, L.Y.; Hu, X. Low-temperature and single-step synthesis of $\mathrm{N}$-doped porous carbons with a high $\mathrm{CO}_{2}$ adsorption performance by sodium amide activation. Energy Fuels 2018, 32, 10830-10837. [CrossRef]

36. Li, Y.; Li, D.W.; Rao, Y.; Zhao, X.B.; Wu, M.B. Superior $\mathrm{CO}_{2}, \mathrm{CH}_{4}$, and $\mathrm{H}_{2}$ uptakes over ultrahigh-surface-area carbon spheres prepared from sustainable biomass-derived char by $\mathrm{CO}_{2}$ Activation. Carbon 2016, 105, 454-462. [CrossRef]

37. Yao, K.X.; Chen, Y.L.; Lu, Y.; Zhao, Y.F.; Ding, Y. Ultramicroporous carbon with extremely narrow pore distribution and very high nitrogen doping for efficient methane mixture gases Upgrading. Carbon 2017, 122, 258-265. [CrossRef]

38. Wu, X.F.; Yuan, B.; Bao, Z.B.; Deng, S.G. Adsorption of carbon dioxide, methane and nitrogen on an ultramicroporous copper metal-organic framework. J. Colloid Interface Sci. 2014, 430, 78-84. [CrossRef]

39. Wu, Y.; Muthukrishnan, A.; Nagata, S.; Nabae, Y. Kinetic understanding of the reduction of oxygen to hydrogen peroxide over an N-doped carbon electrocatalyst. J. Phys. Chem. C 2019, 123, 4590-4596. [CrossRef]

40. Li, Y.; Xu, R.; Wang, X.; Wang, B.B.; Cao, J.L.; Yang, J.; Wei, J.P. Waste wool derived nitrogen-doped hierarchical porous carbon for selective $\mathrm{CO}_{2}$ capture. RSC Adv. 2018, 8, 19818-19826. [CrossRef]

41. Tian, W.J.; Zhang, H.Y.; Sun, H.Q.; Suvorova, A.; Saunders, M.; Tade, M.; Wang, S.B. Heteroatom (N or $\mathrm{N}-\mathrm{S}$ )-doping induced layered and honeycomb microstructures of porous carbons for $\mathrm{CO}_{2}$ capture and energy applications. Adv. Funct. Mater. 2016, 26, 8651-8661. [CrossRef]

42. Raganati, F.; Chirone, R.; Ammendola, P. Gas-solid fluidization of cohesive powders. Chem. Eng. Res. Des. 2018, 133, 347-387. [CrossRef]

43. Van Ommen, J.R.; Valverde, J.M.; Pfeffer, R. Fluidization of nanopowders: A review. J. Nanopart. Res. 2012, 14, 737. [CrossRef] [PubMed]

44. Valverde, J.M.; Quintanilla, M.A.S.; Castellanos, A.; Lepek, D.; Quevedo, J.; Dave, R.N.; Pfeffer, R. Fluidization of fine and ultrafine particles using nitrogen and neon as fluidizing gases. AIChE J. 2008, 54, 86-103. [CrossRef]

45. Monazam, E.R.; Spenik, J.; Shadle, L.J. Fluid bed adsorption of carbon dioxide on immobilized polyethylenimine (PEI): Kinetic analysis and breakthrough behavior. Chem. Eng. J. 2013, 223, 795-805. [CrossRef]

46. Raganati, F.; Chirone, R.; Ammendola, P. Effect of temperature on fluidization of geldart's group A and C powders: Role of interparticle forces. Ind. Eng. Chem. Res. 2017, 56, 12811-12821. [CrossRef]

47. Chirone, R.; Raganati, F.; Ammendola, P.; Barletta, D.; Lettieri, P.; Poletto, M. A comparison between interparticle forces estimated with direct powder shear testing and with sound assisted fluidization. Powder Technol. 2018, 323, 1-7. [CrossRef]

48. Raganati, F.; Ammendola, P.; Chirone, R. Role of acoustic fields in promoting the gas-solid contact in a fluidized bed of fine particles. KONA Powder Part. J. 2015, 32, 23-40. [CrossRef]

49. Raganati, F.; Ammendola, P.; Chirone, R. $\mathrm{CO}_{2}$ capture performances of fine solid sorbents in a sound-assisted fluidized bed. Powder Technol. 2014, 268, 347-356. [CrossRef] 
50. Zhang, H.W.; Lu, J.M.; Yang, L.; Hu, M.X.; Huang, Z.H.; Lu, R.T.; Kang, F.Y. N, S co-doped porous carbon nanospheres with a high cycling stability for sodium ion batteries. New Carbon Mater. 2017, 32, 517-526. [CrossRef]

51. Du, X.; Ma, S.H.; Zhao, W.; Zheng, Z.L.; Qi, T.; Wang, Y. Glucose-based activated carbon spheres as electrode material for electrochemical capacitor. J. Nanosci. Nanotechnol. 2017, 17, 3835-3841. [CrossRef]

52. Li, M.; Li, W.; Liu, S.X. Hydrothermal synthesis, characterization, and $\mathrm{KOH}$ activation of carbon spheres from glucose. Carbohydr. Res. 2011, 346, 999-1004. [CrossRef] [PubMed]

53. Sun, X.M.; Li, Y.D. Colloidal carbon spheres and their core/shell structures with noble-metal nanoparticles. Angew. Chem. Int. Ed. 2004, 43, 597-601. [CrossRef] [PubMed]

54. Li, M.; Li, W.; Liu, S.X. Control of the morphology and chemical properties of carbon spheres prepared from glucose by a hydrothermal method. J. Mater. Res. 2012, 27, 1117-1123. [CrossRef]

55. Wang, Q.; Li, H.; Chen, L.Q.; Huang, X.J. Novel spherical microporous carbon as anode material for Li-ion batteries. Solid State Ion. 2002, 152-153, 43-50. [CrossRef]

56. Liu, S.B.; Zhao, Y.; Zhang, B.H.; Xia, H.; Zhou, J.F.; Xie, W.K.; Li, H.J. Nano-micro carbon spheres anchored on porous carbon derived from dual-biomass as high rate performance supercapacitor electrodes. J. Power Sources 2018, 381, 116-126. [CrossRef]

57. Мa, X.; Cao, M.; Hu, C. Bifunctional $\mathrm{HNO}_{3}$ catalytic synthesis of $\mathrm{N}$-doped porous carbons for $\mathrm{CO}_{2}$ capture. J. Mater. Chem. A 2013, 1, 913-918. [CrossRef]

58. Shao, C.F.; Qiu, S.J.; Chu, H.L.; Zou, Y.J.; Xiang, C.L.; Xu, F.; Sun, L.X. Nitrogen-doped porous microsphere carbons derived from glucose and aminourea for high-performance supercapacitors. Catal. Today 2018, 318, 150-156. [CrossRef]

59. Sing, K.S.W. Reporting physisorption data for gas/solid systems-with special reference to the determination of surface area and porosity (Recommendations 1984). Pure Appl. Chem. 1985, 57, 603-619. [CrossRef]

60. Xu, L.Q.; Guo, L.P.; Hu, G.S.; Chen, J.H.; Hu, X.; Wang, S.L.; Dai, W.; Fan, M.H. Nitrogen-doped porous carbon spheres derived from D-glucose as highly-efficient $\mathrm{CO}_{2}$ sorbents. RSC Adv. 2015, 5, 37964-37969. [CrossRef]

61. Chandra, V.; Yu, S.U.; Kim, S.H.; Yoon, Y.S.; Kim, D.Y.; Kwon, A.H.; Meyyappan, M.; Kim, K.S. Highly selective $\mathrm{CO}_{2}$ capture on $\mathrm{N}$-doped carbon produced by chemical activation of polypyrrole functionalized graphene sheets. Chem. Commun. 2012, 48, 735-737. [CrossRef] [PubMed]

62. Wang, Z.H.; Qie, L.; Yuan, L.X.; Zhang, W.X.; Hu, X.L.; Huang, Y.H. Functionalized N-doped interconnected carbon nanofibers as an anode material for sodium-ion storage with excellent performance. Carbon 2013, 55, 328-334. [CrossRef]

63. Hao, G.P.; Jin, Z.Y.; Sun, Q.; Zhang, X.Q.; Zhang, J.T.; Lu, A.H. Porous carbon nanosheets with precisely tunable thickness and selective $\mathrm{CO}_{2}$ adsorption properties. Energy Environ. Sci. 2013, 6, 3740-3747. [CrossRef]

64. Lin, Z.J.; Hu, X.B.; Huai, Y.J.; Deng, Z.H. Preparation and characterization of a new carbonaceous material for electrochemical systems. J. Serb. Chem. Soc. 2010, 75, 271-282. [CrossRef]

65. Zhou, L.; Cao, H.; Zhu, S.Q.; Hou, L.R.; Yuan, C.Z. Hierarchical micro-/mesoporous N- and O-enriched carbon derived from disposable cashmere: A competitive cost-effective material for high-performance electrochemical capacitors. Green Chem. 2015, 17, 2373-2382. [CrossRef]

66. Wang, J.; Krishna, R.; Yang, J.F.; Deng, S.G. Hydroquinone and quinone-grafted porous carbons for highly selective $\mathrm{CO}_{2}$ capture from flue gases and natural gas upgrading. Environ. Sci. Technol. 2015, 49, 9364-9373. [CrossRef]

67. Myers, A.L.; Prausnitz, J.M. Thermodynamics of mixed-gas adsorption. AIChE J. 1965, 11, 121-127. [CrossRef]

68. Walton, K.S.; Sholl, D.S. Predicting Multicomponent adsorption: 50 years of the ideal adsorbed solution theory. AIChE J. 2015, 61, 2757-2762. [CrossRef]

69. Abdelmoaty, Y.H.; Tessema, T.D.; Norouzi, N.; El-Kadri, O.M.; Turner, J.B.M.; El-Kaderi, H.M. Effective approach for increasing the heteroatom doping levels of porous carbons for superior $\mathrm{CO}_{2}$ capture and separation performance. ACS Appl. Mater. Interfaces 2017, 9, 35802-35810. [CrossRef]

70. Zhou, X.; Huang, W.Y.; Miao, J.P.; Xia, Q.B.; Zhang, Z.J.; Wang, H.H.; Li, Z. Enhanced separation performance of a novel composite material GrO@MIL-101 for $\mathrm{CO}_{2} / \mathrm{CH}_{4}$ binary mixture. Chem. Eng. J. 2015, 266, 339-344. [CrossRef]

71. Sethia, G.; Sayari, A. Comprehensive study of ultra-microporous nitrogen-doped activated carbon for $\mathrm{CO}_{2}$ capture. Carbon 2015, 93, 68-80. [CrossRef] 
72. RudziŃqski, W.; Nieszporek, K.; Moon, H.; Rhee, H.-K. On the theoretical origin and applicability of the potential theory approach to predict mixed-gas adsorption on solid surfaces from single-gas adsorption isotherms. Chem. Eng. Sci. 1995, 50, 2641-2660. [CrossRef]

73. Khalili, S.; Khoshandam, B.; Jahanshahi, M. Synthesis of activated carbon/polyaniline nanocomposites for enhanced $\mathrm{CO}_{2}$ adsorption. RSC Adv. 2016, 6, 35692-35704. [CrossRef]

74. Nieszporek, K.; Banach, T. Adsorption of binary gas mixtures on strongly heterogeneous surfaces. Sep. Sci. Technol. 2012, 47, 482-493. [CrossRef]

75. Nieszporek, K.; Banach, T. Influence of energetic heterogeneity and lateral interactions between adsorbed molecules on the kinetics of gas adsorption. Ind. Eng. Chem. Res. 2011, 50, 3078-3088. [CrossRef]

76. Nieszporek, K.; Banach, T. Theoretical prediction of gas adsorption kinetics based on equilibrium data. Can. J. Chem. 2012, 90, 828-835. [CrossRef]

(C) 2020 by the authors. Licensee MDPI, Basel, Switzerland. This article is an open access article distributed under the terms and conditions of the Creative Commons Attribution (CC BY) license (http://creativecommons.org/licenses/by/4.0/). 